\title{
Use of the Airway Questionnaire 20 to detect changes in quality of life in asthmatic patients and its association with the St George's Respiratory Questionnaire and clinical parameters
}

\author{
Thida Win MRCP ${ }^{1}$, Linda Pearce MSc RN ${ }^{1}$, James Nathan MRCP ${ }^{1}$, Fay Cafferty MMath ${ }^{2}$, Clare Laroche FRCP ${ }^{1}$
}

\begin{abstract}
T Win, L Pearce, J Nathan, F Cafferty, C Laroche. Use of the Airway Questionnaire 20 to detect changes in quality of life in asthmatic patients and its association with the St George's Respiratory Questionnaire and clinical parameters. Can Respir J 2008;15(3):133-137.
\end{abstract}

BACKGROUND AND OBJECTIVES: The usefulness of the Airway Questionnaire 20 (AQ20) - a short version of the St George's Respiratory Questionnaire (SGRQ) - to evaluate quality of life (QOL) in asthmatic patients following a hospital admission was assessed.

METHODS: At baseline and at six months following the index admission, 135 asthmatic patients were asked to complete the AQ20 and the SGRQ. The patient's peak flow, number of subsequent asthma exacerbations and number of repeat hospital admissions were also recorded.

RESULTS: The AQ20 scores ranged from 0 to 20, with a high score indicating poor QOL. The AQ20 had good coverage, with no obvious ceiling or floor effects. In multiple regression analysis, all three SGRQ components were important in predicting AQ20 scores $\left(\mathrm{R}^{2}\right.$ values were $61.9 \%$ and $73.1 \%$ for baseline and six-month scores, respectively). The AQ20 was closely correlated with the SGRQ, but not redundant when used together. Bias was low when the retest reliability of the AQ20 was evaluated using the Bland-Altman method, but variation was high $(-0.64)$. Patients with subsequent exacerbations $(n=52)$ had higher AQ20 scores at six-month follow-up $(\mathrm{P}=0.002)$. In logistic regression, the AQ20 score was closely associated with the incidence of exacerbations (OR 1.15, 95\% CI 1.05 to 1.25), with a similar magnitude of association between the AQ20 and the SGRQ. The AQ20 score did not correlate with peak flow at baseline $(\mathrm{r}=-0.05 ; \mathrm{P}=0.573)$ or at six months $(\mathrm{r}=-0.31 ; \mathrm{P}=0.006)$, and was not responsive to changes in peak flow $(r=-0.06 ; \mathrm{P}=0.583)$.

CONCLUSION: The AQ20 can be substituted for the more complicated SGRQ in the assessment of QOL in patients following a hospital admission for an asthma exacerbation.

Key Words: AQ20; Asthma; Peak flow; Quality of life; SGRQ

Iealth-related quality of life (HRQOL) has become an Himportant outcome in respiratory patients, as shown by the development of several HRQOL questionnaires. Among them is the St George's Respiratory Questionnaire (SGRQ), which is now one of the most widely used instruments for assessing HRQOL in respiratory patients $(1,2)$. However, the use of this questionnaire is restricted mainly to research
L'utilisation du questionnaire en 20 questions sur les voies aériennes pour déceler les changements à la qualité de vie des patients asthmatiques et son association avec le questionnaire respiratoire du St. George Hospital et ses paramètres cliniques

HISTORIQUE ET OBJECTIFS : Les auteurs ont analysé l'utilité du questionnaire en 20 questions sur les voies aériennes (AQ20), une version courte du questionnaire respiratoire du St. George Hospital (QRSG), pour évaluer la qualité de vie (QDV) des patients asthmatiques après une hospitalisation.

MÉTHODOLOGIE : Au moment de l'hospitalisation et six mois plus tard, on a demandé à 135 patients asthmatiques de remplir l'AQ20 et le QRSG. Chaque patient a également précisé son débit de pointe, le nombre d'exacerbations subséquentes de l'asthme et le nombre de réhospitalisations.

RÉSULTATS : Les indices de l'AQ20 variaient entre 0 et 20, un indice élevé démontrant une mauvaise QDV. L'AQ20 offrait une bonne couverture, sans effet de plafonnement ou effet plancher évident. Dans l'analyse de régression multiple, les trois éléments du QRSG étaient importants pour prévoir les indices de l'AQ20 (les valeurs $\mathrm{R}^{2}$ étaient de $61,9 \%$ et de $73,1 \%$ pour les indices de départ et au bout de six mois, respectivement). L'AQ20 étaient étroitement relié au QRSG, mais pas redondant lorsque les deux questionnaires étaient utilisés conjointement. Le biais était faible lorsqu'on vérifiait la fiabilité de l'AQ20 par contretest au moyen de la méthode de Bland-Altman, mais la variation était élevée $(-0,64)$. Les patients ayant des exacerbations subséquentes $(n=52)$ présentaient des indices d'AQ20 plus élevés au suivi de six mois $(\mathrm{P}=0,002)$. Dans le cadre de la régression logistique, l'indice d'AQ20 était étroitement relié à l'incidence des exacerbations (RR 1,15, 95 \% IC 1,05 à 1,25), la magnitude d'association entre l'AQ20 et le QRSG étant similaire. L'indice d'AQ20 n'était pas relié au débit de pointe de départ $(\mathrm{r}=-0,05 ; \mathrm{P}=0,573)$ ou au suivi de six mois $(\mathrm{r}=-0,31 ; \mathrm{P}=0,006)$, et ne réagissait pas aux variations du débit de pointe $(\mathrm{r}=-0,06 ; \mathrm{P}=0,583)$.

CONCLUSION : On peut utiliser l'AQ20 pour remplacer le QRSG plus complexe dans l'évaluation de la QDV des patients après une hospitalisation en raison d'une exacerbation de l'asthme.

settings because its interpretation is difficult and it takes a significant amount of time to complete. The SGRQ consists of two parts. Part one includes eight sets of questions, and part two has six sections. Each section has four to 10 sets of questions. The five-page questionnaire can take up to $20 \mathrm{~min}$ to $30 \mathrm{~min}$ to complete and also needs a statistician to analyze the results.

${ }^{1}$ Respiratory Medicine, West Suffolk Hospital, Bury St Edmunds, Suffolk; ${ }^{2} \mathrm{MRC}$ Biostatistics Unit, Institute of Public Health, Cambridge, United Kingdom

Correspondence: Dr Thida Win, Department of General and Respiratory Medicine, Lister Hospital, Stevenage SG1 4AB, United Kingdom.

Telephone 44-1438-781649, fax 44-1438-781199, e-mail drthidawin@hotmail.com 
The Airway Questionnaire 20 (AQ20) was developed for patients with asthma and chronic obstructive pulmonary disease (COPD) (3). It contains 20 items, with scores ranging from 0 to 20 - high scores indicate poor QOL. It takes only a few minutes to complete and has been validated in asthma (4) and COPD (5) patients. However, it has been suggested that the AQ20 may be less responsive than the SGRQ because it measures fewer items. We postulated that the clinical parameters used to assess asthma severity - such as peak flow, number of asthma exacerbations and number of hospital admissions for asthma - may be associated with a patient's QOL. However, there is limited data on the relationship between QOL and these clinical parameters.

The aim of the present study was to evaluate the relationship of the AQ20 to recurrent asthma exacerbations, incidence of hospital readmissions and changes in peak flow, and to assess the reliability and redundancy of the AQ20 compared with the SGRQ in asthma patients after a hospital admission.

\section{METHODS}

All patients older than 16 years of age who were admitted to a hospital with acute asthma between October 2000 and October 2003 were eligible for the trial. Of 373 eligible patients admitted with acute asthma, 154 were enrolled in the study. A clinical diagnosis of asthma was made if the symptoms of wheezing, breathlessness and cough met the criteria as per the British Thoracic Society guidelines (6). Peak flow measurements were also used to diagnose asthma. Patients subsequently found to have COPD were excluded at the first follow-up appointment. A diagnosis of COPD was defined as a patient with a forced expiratory volume in $1 \mathrm{~s}\left(\mathrm{FEV}_{1}\right)$ of less than $80 \%$ of predicted and an $\mathrm{FEV}_{1} /$ forced vital capacity of less than $70 \%$ of predicted, with no significant improvement following a two-week course of steroids. Patients with pneumonia and interstitial lung disease were excluded from the study. Subjects underwent an initial assessment and then a follow-up assessment after six months. Peak flow measurements, number of recurrent exacerbations and number of hospital attendances for emergency treatment were recorded. Patients were asked to complete the AQ20 QOL questionnaire and the SGRQ during their initial visit and at the six-month follow-up assessment.

\section{QOL questionnaires}

The AQ20 scores are out of a total of 20, with high scores indicating a poor QOL. The SGRQ has three dimensions (symptoms, activity and impacts), and these can be summed to give a total score (expressed as a percentage). High scores represent a poor QOL.

\section{Validity, redundancy and test-retest reliability of QOL questionnaires}

The AQ20 scores were assessed for coverage, as well as for ceiling or floor effects, through descriptive statistics and inspection of histograms. The validity of the AQ20 was assessed by its correlation with SGRQ scores. Multiple linear regression was used to model AQ20 scores with the three components of the SGRQ scores, and linear regression was used to model AQ20 with the total SGRQ score. The aim was to test the redundancy of the AQ20 when used in conjunction with the SGRQ, by examining whether any of the components of the SGRQ could explain the variations in the AQ20. If the two questionnaires were redundant, then the variation seen in one score could be entirely explained by one or more of the components of the other score. In other words, when the SGRQ components were used to predict AQ20 scores in multiple regression, $\mathrm{R}^{2}$ was close to $100 \%$. This would imply that the AQ20 is not measuring any aspect of asthma severity over and above that which is measured by the SGRQ, and is therefore redundant.

A subset analysis of the patients who did not experience any exacerbations was performed. These patients were assumed to be clinically stable. This enabled an assessment of the testretest reliability of the questionnaire using Pearson's correlation coefficient and other methods for measuring agreement, as proposed by Bland and Altman (7).

Relationship between QOL questionnaire and peak flow The construct validity of the SGRQ and the AQ20 was assessed by considering how well the questionnaire scores correlated with peak flow values, with predicted peak flow measured as a percentage of best peak flow. This analysis was performed separately as a spot measurement in clinics at baseline and after six months.

Relationship between QOL questionnaire and exacerbation An exacerbation was defined as a drop in peak flow greater than $30 \%$ of the best predicted or recorded value, requiring any of the following: increased use of inhaled corticosteroids, use of an emergency nebulized bronchodilator or a course of oral corticosteroids.

The study population was split into two groups. Patients who experienced exacerbations during the six-month follow-up period formed one group, and those who did not experience any exacerbations formed the other group. A two-sample $t$ test was used to assess how well the AQ20 scores at six months distinguished between these two groups. Logistic regression was used to determine whether the QOL scores were predictive of patients who experienced subsequent exacerbations.

\section{Relationship between QOL questionnaire and hospital admission}

The Mann-Whitney U (nonparametric) test was used to compare six-month QOL scores with the incidence of repeat hospital admissions within the six-month follow-up period.

\section{RESULTS}

The mean age of the patients was 40 years (range of 17 to 86 years of age). Mean predicted peak flow was $513 \mathrm{~L} / \mathrm{min}$. On discharge from hospital, mean peak flow was $442 \mathrm{~L} / \mathrm{min}$, and at six-month follow-up it was $424 \mathrm{~L} / \mathrm{min}$. Forty-seven per cent of the subjects $(n=72)$ in the present study population had no asthma exacerbations during the six-month follow-up period, compared with the other $52 \%$ of patients $(n=80)$ who did (information was not available for two subjects).

\section{Validity of the questionnaires}

The AQ20 scores covered approximately the whole range both at baseline (mean $[ \pm \mathrm{SD}]$ score $7.66 \pm 4.69)$, range 0 to 18 ) and at six-month follow-up (mean score $8.00 \pm 5.03$, range 0 to 19 ), indicating good coverage. Both were approximately normally distributed, with no clear evidence of a ceiling or floor effect (Figure 1). 


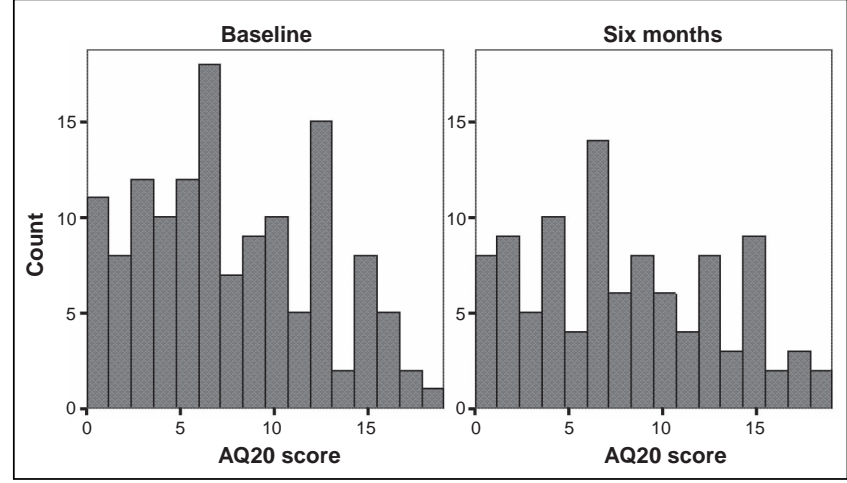

Figure 1) Distribution of Airway Questionnaire 20 (AQ20) scores at baseline and at six-month follow-up

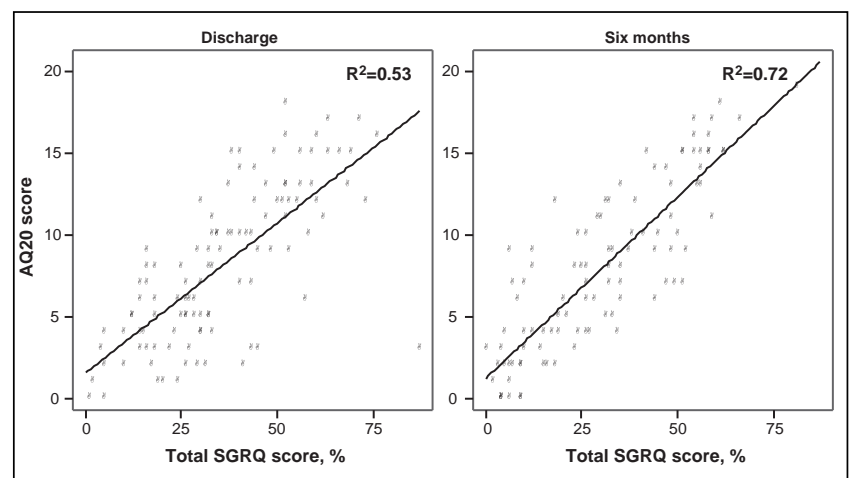

Figure 2) Pearson's correlation coefficient between the St George's Respiratory Questionnaire (SGRQ) and the Airway Questionnaire 20 (AQ20) at discharge $(r=0.72 ; P<0.001)$ and at six-month follow-up $(r=0.85 ; P<0.001)$

\section{Redundancy of the questionnaires}

There was evidence of strong linear correlation between the AQ20 and SGRQ scores, with higher AQ20 scores being associated with higher SGRQ scores. Figure 2 shows the scatter plot of AQ20 against total SGRQ score. Pearson's correlation coefficient between SGRQ and AQ20 was $0.72(\mathrm{P}<0.001)$ at baseline and $0.85(\mathrm{P}<0.001)$ at six months. In univariate analysis, the total SGRQ score was found to be important in predicting AQ20 at both baseline and at six-month follow-up assessment $\left(\mathrm{R}^{2}=52.7 \%[\mathrm{P}<0.001]\right.$ and $\mathrm{R}^{2}=72.3 \%[\mathrm{P}<0.001]$, respectively).

In multiple regression analysis, all three components of the SGRQ were found to be important in predicting AQ20 scores both at baseline (impact, $\mathrm{P}<0.001$; activity, $\mathrm{P}<0.001$; and symptoms, $\mathrm{P}=0.020 ; \mathrm{R}^{2}=61.9 \%$ ) and at six months (impact, $\mathrm{P}<0.001$; activity, $\mathrm{P}=0.005$; and symptoms, $\mathrm{P}=0.064$; $\left.\mathrm{R}^{2}=73.1 \%\right)$.

Test-retest reliability of the questionnaires

The test-retest reliability of the AQ20 was assessed by comparing baseline scores with six-month scores in the subgroup of patients who did not experience any exacerbations $(n=47)$. These patients were assumed to be clinically stable during the study period. The Pearson's correlation coefficient between baseline and six-month AQ20 scores was $0.72(\mathrm{P}<0.001)$. Bias (or mean $[ \pm \mathrm{SD}]$ difference) was $-0.64 \pm 3.98$, with $95 \%$ limits of agreement of -8.44 to 7.17 . Figure 3 shows the difference in AQ20 score plotted against the mean AQ20 score for each

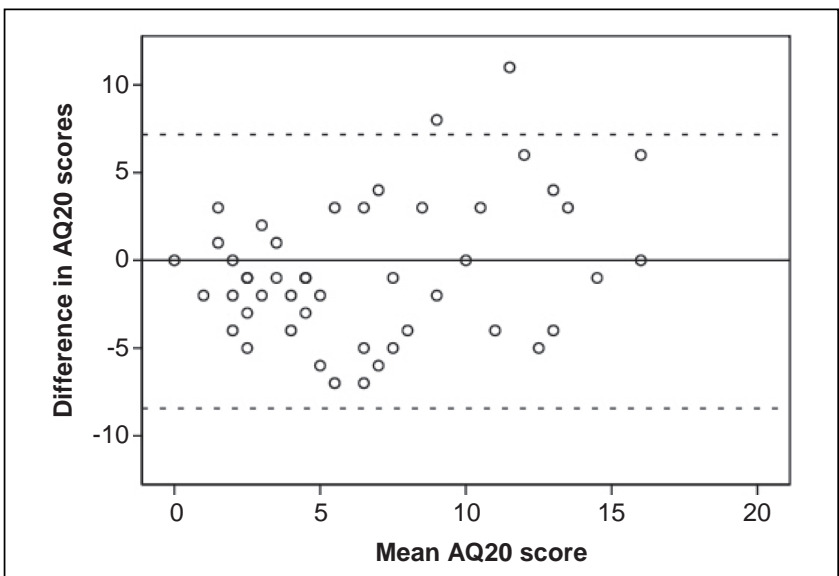

Figure 3) Test-retest reliability of the Airway Questionnaire 20 (AQ20) with 95\% limits of agreement (indicated by dotted lines). Difference versus mean AQ20 (only patients with no exacerbations)

\section{TABLE 1}

\begin{tabular}{|c|c|c|c|c|c|c|}
\hline & \multicolumn{2}{|c|}{$\begin{array}{c}\text { Baseline } \\
\text { assessment }\end{array}$} & \multicolumn{2}{|c|}{$\begin{array}{c}\text { Six-month } \\
\text { assessment }\end{array}$} & \multicolumn{2}{|c|}{$\begin{array}{l}\text { Change } \\
\text { in scores }\end{array}$} \\
\hline & $r$ & $\mathbf{P}$ & $r$ & $\mathbf{P}$ & $r$ & $\mathbf{P}$ \\
\hline Peak flow & -0.05 & 0.573 & -0.31 & 0.006 & -0.06 & 0.583 \\
\hline Symptoms & 0.56 & $<0.001$ & 0.69 & $<0.001$ & 0.47 & $<0.001$ \\
\hline Activity & 0.69 & $<0.001$ & 0.72 & $<0.001$ & 0.67 & $<0.001$ \\
\hline Impact & 0.72 & $<0.001$ & 0.83 & $<0.001$ & 0.55 & $<0.001$ \\
\hline Total SGRQ & 0.72 & $<0.001$ & 0.85 & $<0.001$ & 0.64 & $<0.001$ \\
\hline
\end{tabular}

*Pearson's correlation coefficient

patient, along with the $95 \%$ limits of agreement (indicated by dotted lines).

Relationship between QOL questionnaire and peak flow There was no correlation between the AQ20 score and peak flow at baseline $(r=-0.05 ; \mathrm{P}=0.573)$ or at six-month follow-up $(\mathrm{r}=-0.31 ; \mathrm{P}=0.006)$, shown in Table 1 . There was also no evidence that the AQ20 was responsive to changes in peak flow between the two assessments $(r=-0.06 ; \mathrm{P}=0.583)$. Pearson's correlation between SGRQ scores and peak flow at baseline was -0.064 ( $\mathrm{P}=0.536)$; at six-month follow-up, -0.247 $(\mathrm{P}=0.031)$. There was no evidence that SGRQ was responsive to changes in peak flow over the six-month period $(\mathrm{r}=-0.146$; $\mathrm{P}=0.211$ ).

Relationship between QOL questionnaire and exacerbation Forty-seven patients in the present study population had no asthma exacerbations during the six-month follow-up period, compared with the other 52 patients who did (information was not available for two subjects). The mean AQ20 score at six months was $6.32 \pm 5.26$ in the group of patients with no exacerbations and $9.48 \pm 4.38(\mathrm{P}=0.002)$ in the group that experienced exacerbations. In univariate logistic regression, both the AQ20 score (OR 1.15, 95\% CI 1.05 to 1.25) and the SGRQ score (OR 1.03, 95\% CI 1.01 to 1.06 ) were significantly 
associated with patients experiencing exacerbations during the follow-up period.

\section{Relationship between hospital admission and QOL}

Seven patients were readmitted to hospital during the sixmonth period. There was no significant difference between median six-month AQ20 scores in the group who had not been readmitted (median 8 , interquartile range [IQR] 8) and those who had (median 7, IQR 9; $\mathrm{P}=0.328$ ). However, using the SGRQ, the median six-month score for the group without readmissions was 26 (IQR 37) compared with 47 (IQR 7) in the group who had experienced a readmission $(\mathrm{P}=0.031)$.

\section{DISCUSSION}

There was a relatively low participation rate in the present study because only $41 \%$ of eligible patients (154 of 373 ) were recruited. This may be partly explained by several factors. For example, researchers may not have had an opportunity to recruit patients who were admitted over the weekend, late at night or overnight, which are common periods of admission in asthmatic patients. Most of our asthmatic patients were young and had school or work commitments, making the additional time and commitment to our clinics difficult. The study was run to assess QOL after a hospital admission, rather than to change management, which may have led to a lack of motivation and interest for some patients to participate in the study. A further 19 patients were unable to complete the study because they did not attend the six-month follow-up appointment. It is well recognized that poor compliance and poor attendance at follow-up clinics are important factors in patients with poorly controlled asthma. However, there did not appear to be any selection bias. The 19 patients who were unable to complete the study had a similar degree of asthma severity as the rest of the group, and also had no more exacerbations or hospital admissions.

The AQ20 scores in our study population of asthmatic patients showed good distribution, with no evidence of ceiling or floor effects. This contradicted previous findings in which AQ20 scores were skewed toward the mild end of the QOL scale in COPD (3) and asthmatic (8) patients. The reason for the difference in our findings may be partly explained by the fact that we studied a more severe group of asthmatic patients. Our patients were posthospital admission for an asthma exacerbation, whereas in the other study (8), patients were newly diagnosed with asthma.

The present study demonstrated a close correlation between AQ20 and SGRQ scores in asthmatic patients. This finding has previously been reported in COPD patients (3). Our data also suggested that the AQ20 had similar responsiveness to changes in the SGRQ scores, as previously reported by Sanjuás et al (9). Similar trends were seen when the three components of the SGRQ scores were considered separately. This indicates that, while a high proportion of the variation seen in AQ20 scores can be explained by these components, some unexplained variation remains, and so the AQ20 is not redundant when used in conjunction with the SGRQ. However, the reverse is also true, ie, if we were to look at how well the AQ20 predicts the SGRQ, we would find that the SGRQ is not entirely redundant when used in conjunction with the AQ20.

There was no evidence of correlation between the AQ20 score and peak flow as a proportion of best predicted value at baseline assessment. Similarly, there was no evidence that the AQ20 was responsive to changes in peak flow during the follow-up period $(\mathrm{P}=0.583)$. However, at six-month follow-up, higher AQ20 scores were associated with lower peak flow values. This inconsistency may indicate that, while the two variables are associated to some extent, other variables besides peak flow - such as cough and the need to use inhalers regularly - may also influence the way asthma affects QOL. As with the AQ20, the SGRQ seems to have some association with peak flow, but there are likely many other variables, besides peak flow, that affect the way asthma influences patients' QOL. A previous study (3) also concluded that the AQ20 was only weakly associated with $\mathrm{FEV}_{1}$ in COPD patients. In that study, multiple regression analysis revealed that dyspnea and anxiety accounted for $43 \%$ of the variance in the $\mathrm{AQ20}$, whereas dyspnea and maximal oxygen uptake accounted for $61 \%$ of the variance in the total score of the SGRQ.

Our data found that the mean AQ20 score was significantly higher by 3.16 (95\% CI 1.24 to 5.09 ) in patients who had experienced an exacerbation. Logistic regression showed that both the AQ20 and the SGRQ scores were significantly associated with the patients experiencing exacerbations, with higher scores indicating that a subject was more likely to have experienced exacerbations during the six-month period. The AQ20 seems to be at least as useful as the SGRQ in this respect.

Because only seven patients were readmitted to hospital during the six-month period, the study had an insufficient number of patients to assess the relative usefulness of the two QOL questionnaires for identifing differences in QOL between those patients readmitted and those not readmitted. This low readmission rate may have been due to an early follow-up offered to this patient group. There were no differences between the groups as measured by the AQ20 $(\mathrm{P}=0.328)$. The SGRQ did show some evidence of a different score between the two groups, although the statistical power was low. A previous study (10) using a different questionnaire (risk screening questionnaire) found a negative association between QOL and number of hospital attendances. However, to our knowledge, no study has previously looked at the effect of hospital readmission for asthma on QOL.

In recent years, the importance of HRQOL in the evaluation of medical care and intervention practice has been widely acknowledged. In particular, for chronic diseases like asthma or COPD, the multidimensional concept of QOL has adopted the role of an essential outcome parameter. Two types of instruments can be used to categorize QOL: generic instruments, which assess overall QOL, and disease-specific questionnaires, which focus on specific aspects related to a particular disease.

Over the past two decades, more than 1000 QOL instruments have been developed, including nearly 20 disease-specific inventories for patients with chronic lung diseases. In clinical practice, both generic and specific questionnaires are used to assess QOL in patients with asthma and COPD. Disease-specific QOL instruments are considered to be more sensitive in establishing the specific restrictions related to asthma or COPD, and in detecting possible improvements in $\mathrm{QOL}$ after treatment. One study (11) compared two different QOL questionnaires (the SGRQ and the 'Fragebogen zur Lebensqualität bei Asthma') for their properties, limitations and special methodologies. They found that both questionnaires appeared to be 
reliable, valid and efficient for the assessment of QOL in patients with asthma or COPD, and may facilitate decision making in the treatment process. Another study (5) also did a comparative analysis between the AQ20/30 and the SGRQ in patients with COPD and found that they were equally useful. Several other QOL questionnaires - such as the Juniper Mini Asthma Quality of Life Questionnaire, the Short Form 12 questionnaire and the Asthma Therapy Assessment Questionnaire were used to assess the relationships among QOL, severity and control measures in asthma. Schatz et al (12) suggested that distinct components of patient-reported asthma health status may be identified by factor analysis. Therefore, all of these studies are in agreement with our findings that different QOL questionnaires have different components and usages.

\section{REFERENCES}

1. Jones PW, Quirk FH, Baveystock CM, Littlejohnes P. A self-complete measure of health status for chronic airflow limitation. The St. George's Respiratory Questionnaire. Am Rev Respir Dis 1992;145:1321-7.

2. Gallefoss F, Bakke PS, Rsgaard PK. Quality of life assessment after patient education in a randomized controlled study on asthma and chronic obstructive pulmonary disease. Am J Respir Crit Care Med 1999; 159:812-7.

3. Hajiro T, Nishimura K, Jones PW, et al. A novel, short, and simple questionnaire to measure health-related quality of life in patients with chronic obstructive pulmonary disease. Am J Respir Crit Care Med 1999;159:1874-8.

4. Barley EA, Quirk FH, Jones PW. Asthma health status measurement in clinical practice: Validity of a new short and simple instrument. Respir Med 1998;92:1207-14.

5. Alemayehu B, Aubert RE, Feifer RA, Paul LD. Comparative analysis of two quality-of-life instruments for patients with chronic obstructive pulmonary disease. Value Health 2002;5:437-42.

6. The BTS/SIGN British Guideline on the Management of Asthma. Thorax 2003;58(Suppl I):i1-94.

\section{CONCLUSION}

Our data have provided evidence that the AQ20 QOL score has good coverage, with no clear ceiling or floor effects. In terms of reliability, it has low bias but high variation. The score is highly correlated with the SGRQ score, although we have found evidence to suggest that it is not redundant in this respect. Both the AQ20 and the SGRQ scores were significantly associated with the incidence of recurrent exacerbations following the index asthma admission, with higher scores (and therefore worse QOL) indicating that a subject is more likely to experience exacerbations during the six-month period. We found both scores to be equally useful in this respect. Therefore, the AQ20 is a useful alternative to the SGRQ in both academic and clinical practice.

7. Bland JM, Altman DG. Statistical methods for assessing agreement between two methods of clinical measurement. Lancet 1986;8:307-10.

8. Oga T, Nishimura K, Tsukino M, Sato S, Hajiro T, Mishima M. Comparison of the responsiveness of different disease-specific health status measures in patients with asthma. Chest 2002;122:1228-33.

9. Sanjuás C, Alonso J, Prieto L, Ferrer M, Broquetas JM, Antó JM. Health-related quality of life in asthma: A comparison between the St George's Respiratory Questionnaire and the Asthma Quality of Life Questionnaire. Qual Life Res 2002;11:729-38.

10. Pilotto LS, Smith BJ, McElroy HJ, et al. Hospital attendance prediction tool also identifies impaired quality of life in adults with asthma in general practice. J Asthma 2003;40:163-9.

11. Mühlig S, Petermann F. [Illness specific data collection on quality of life of patients with asthma and chronic obstructive bronchitis.] Rehabilitation (Stuttg) 1998;37:XXV-XXXVIII.

12. Schatz M, Mosen D, Apter AJ, et al. Relationships among quality of life, severity, and control measures in asthma: An evaluation using factor analysis. J Allergy Clin Immunol 2005;115:1049-55. 


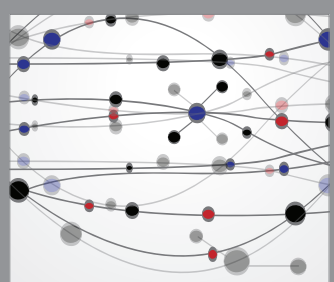

The Scientific World Journal
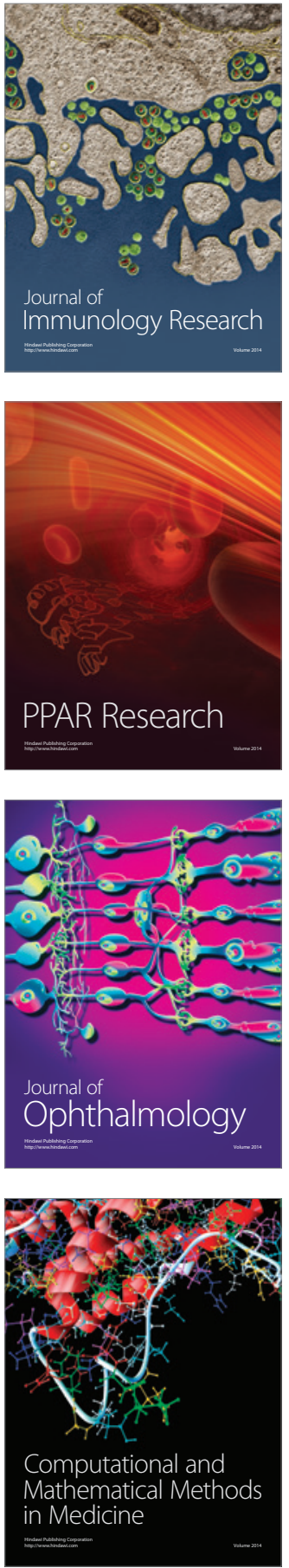

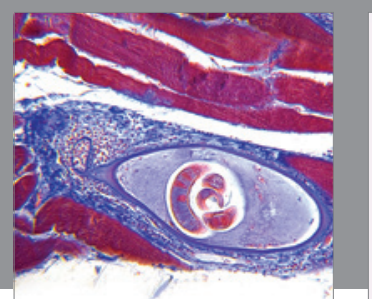

Gastroenterology Research and Practice

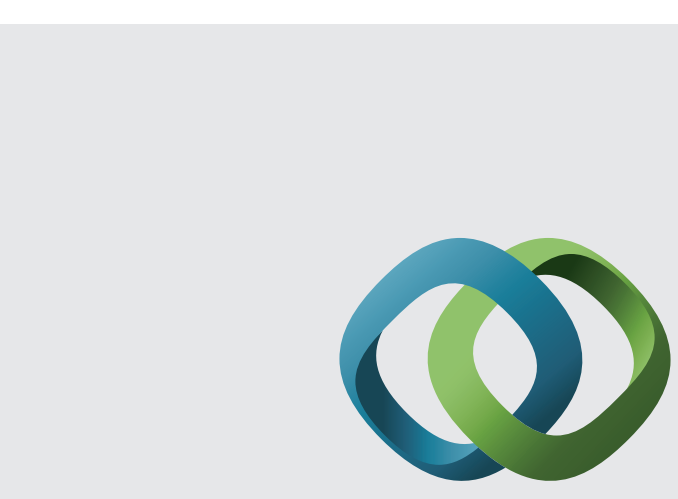

\section{Hindawi}

Submit your manuscripts at

http://www.hindawi.com
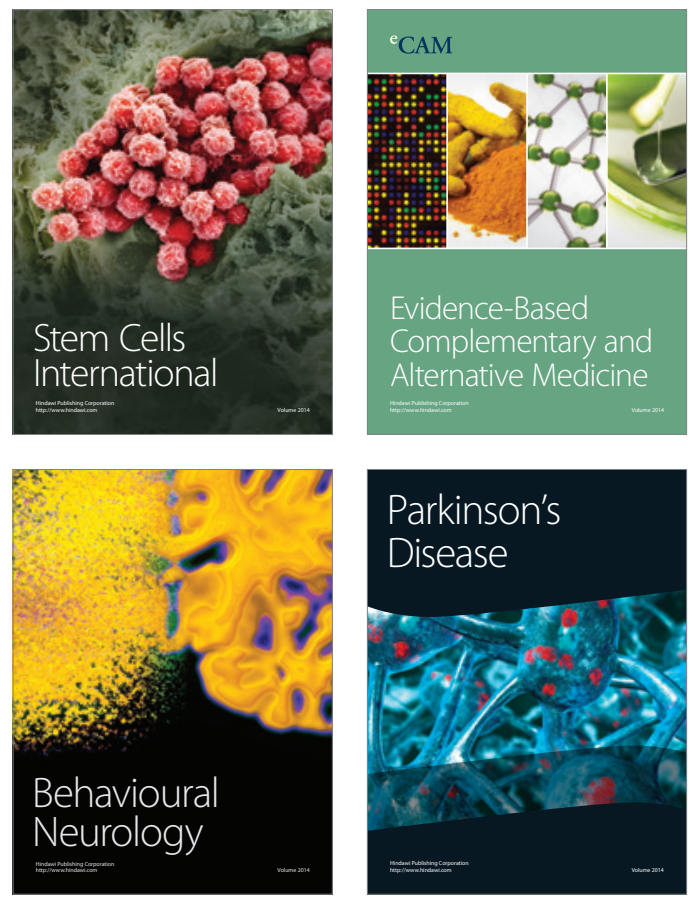
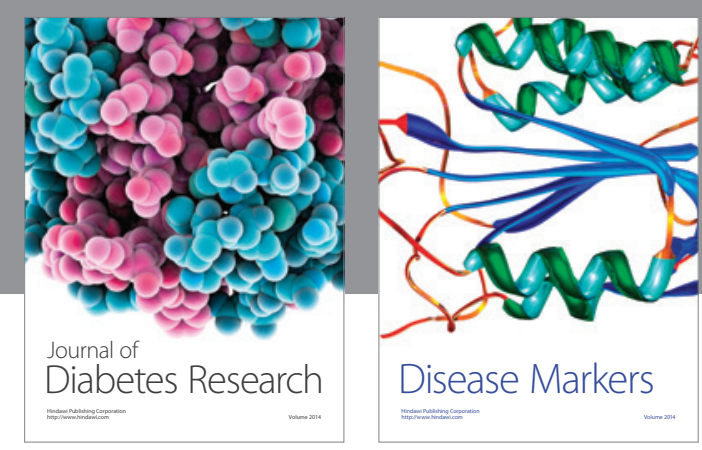

Disease Markers
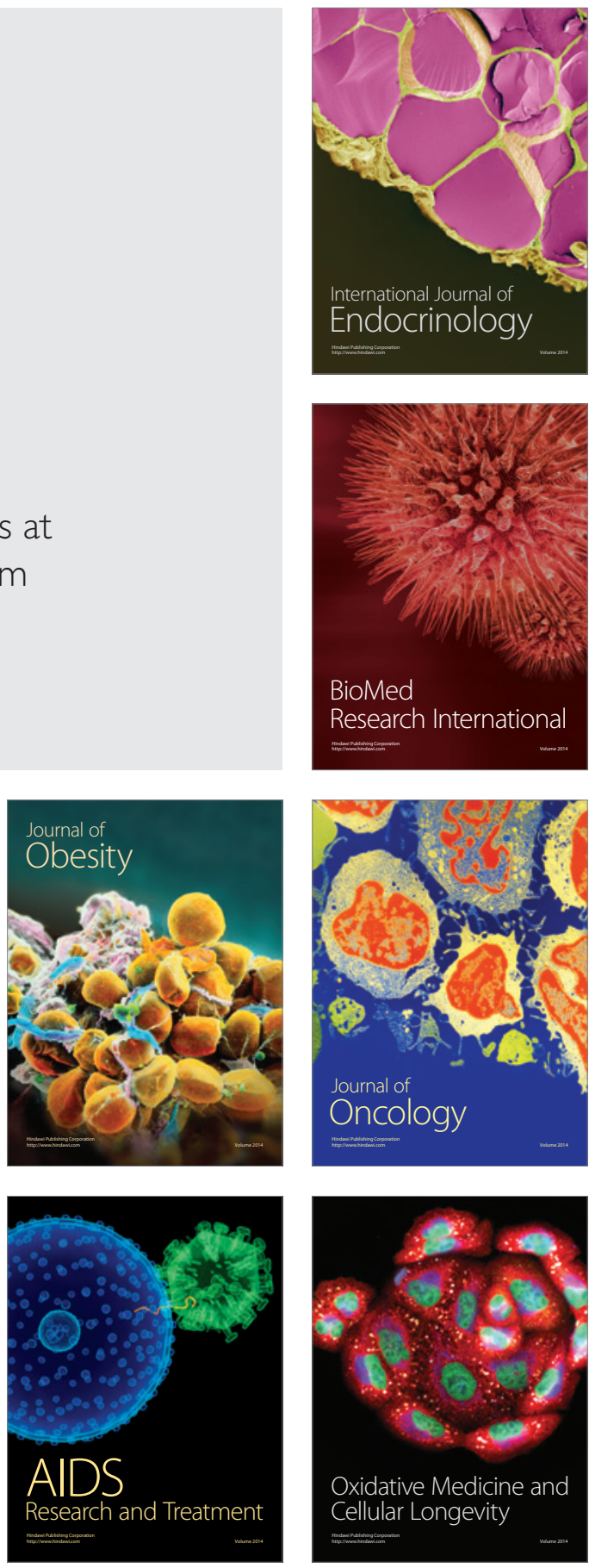